
\title{
aive eResearch
}

eResearch: the open access repository of the research output of Queen Margaret University, Edinburgh

This is an author-formatted version of document published as:

Peppé, Sue JE (2009) Why is prosody in speech-language pathology so difficult? International Journal of Speech-Language Pathology, 11 (4). pp. 258-271. ISSN 1754-9507

\section{Accessed from:}

http://eresearch.qmu.ac.uk/1162/

The published version is available online at:

http://dx.doi.org/10.1080/17549500902906339

\section{Repository Use Policy}

The full-text may be used and/or reproduced, and given to third parties for personal research or study, educational or not-for-profit purposes providing that:

- The full-text is not changed in any way

- A full bibliographic reference is made

- A hyperlink is given to the original metadata page in eResearch

eResearch policies on access and re-use can be viewed on our Policies page:

http://eresearch.qmu.ac.uk/policies.html

Copyright (c) and Moral Rights for this article are retained by the individual authors and/or other copyright owners.

http://eresearch.qmu.ac.uk 
Despite the efforts of David Crystal in the UK in the 1980s (e.g., Crystal, 1982), and many others since, prosody is still a difficult subject for speech-language pathologists. Although it is impossible to speak without using prosody, it is generally allotted comparatively little time or consideration in clinical training. The following paper sets out to investigate why atypical prosody is hard to characterise: the problems of identifying it as distinct from other aspects of communication, the relationship between prosodic phonology and atypical prosody, and the available resources of transcription and assessment. It also aims to identify areas in which research is needed to make prosodic disorder more tractable.

It is necessary first to establish what 'prosody' designates (at least for the purposes of this paper), and what are the communicative functions in which prosody plays a prominent role. The terms and transcription used for prosody are still unsettled and there is disagreement as to the best theoretical models of prosody. The topic in question concerns the manner of speech: it comprises the characteristics of speech deriving from variations in the duration, amplitude and fundamental frequency of speech-sounds, which provide the acoustic realisations of certain communicative functions, to be outlined below. It thus serves to modify the meaning and impact of what is said. The word 'prosody' derives from Greek 'prosodia', which designated matters concerning metre and rhythm in poetry. There is a problem immediately with using the term 'prosody' to refer to the whole topic: a rival one is 'intonation', mainly used by those interested in the theory of this field (e.g., Bolinger 1958, Pierrehumbert 1980, Beckman 1986, Ladd 1997). While 'prosody' may once have been concerned mainly with stress and rhythm (horizontal factors) and 'intonation' with changes in pitch (vertical factors), both terms can now be used to refer to the whole field.

'Suprasegmental' or 'non-segmental' are alternative adjectives, accurate if somewhat negative, defining the topic in contrast with segmental considerations. In this paper 'prosody' will be used as an over-arching term.

Prosodic terminology needs to be established if research in this area is to make any real advances. The lack of agreement on the terminology and scope of the topic, as well as on the best method of transcription, are symptomatic of the elusive nature of prosody and form part of the reason for its 'Cinderella' role in speech research, although a great deal more attention has been accorded it in recent years. Another reason for its relative neglect is that prosody is somewhat invisible, being seldom referred to in normal parlance, in comparison with wordchoice, pronunciation and grammatical structures. 'Tone of voice' may be discussed, but 'stress' is perhaps the only prosodic term in general lay use, where it usually conflates the categories distinguished by intonation phonologists as 'stress' and 'accent'.

\section{Communicative Functions of Prosody}

The functions of prosody have been described as linguistic and paralinguistic (Crystal, 1969; Laver, 1994), i.e. directly affecting the content or meaning of what is said (linguistic) or adding circumstantial information to this (paralinguistic). Of the functions mentioned below, index and affect may be described as paralinguistic, the rest as linguistic (although the pragmatic function is somewhere between the two).

The spheres in which prosody operates have been divided into several areas or communicative functions (Cruttenden, 1997; Couper-Kuhlen, 1986): indexical, affective, grammatical and pragmatic. All the communication functions mentioned below (phrasing, affect, turn-end, focus) involve prosodic variation, but it must be borne in mind that any communicative effect that can be achieved by prosody can also be achieved by other aspects of speech, and sometimes the prosodic cues associated with particular functions are not present. This elusiveness may have led to the notion that prosody is in some ways expendable or merely 
ornamental, and be another reason for its comparative neglect. Prosody is, however, not obliged to reinforce the meanings of the words and the grammatical structures used in speech: subtle messages can be achieved by dissociation. This means that the 'rules' of prosody can be broken correctly and to good effect, thus creating problems for the characterisation of disordered prosody.

Another point to bear in mind is that to say prosody functions in a certain way is not to imply that speakers normally have voluntary control over it. The amount of potential for control varies from function to function, and perhaps if speakers were more aware of the communication effectiveness of prosody they would vary prosodic exponents more than they do, but there is little evidence to suggest that this would be the case. The issue of control is, however, important for clinicians if they are intending to effect changes to a speaker's prosody, and so the topic of control will be allotted some attention in this paper.

\section{Indexical Function}

An individual speaker has (among other speech idiosyncrasies including a characteristic voice quality) established speaking parameters: a habitual speaking pitch-height; a pitch-span, or normal range of pitch variation; a usual rate of speech; and a normal loudness or volume level. Within these, variation occurs to achieve other prosodic functions, which will be described below. Speakers can also have distinctive speech-rhythms, including habitual degrees of emphasis, and frequently-used intonation patterns. It is important for theorists to bear this in mind when generalising about the exponency of prosodic functions, as it results in wide variation of prosodic realisation. Speakers will also sometimes have a regional accent: regional speech differences are generally described in terms of segmental quality, especially vowels, but there is of course a prosodic element to them. Perhaps the best-known example is intonational uptalk (e.g., "Today we have a special?"), otherwise known as the high-rising terminal (Cruttenden, 1994), which appears to have begun as a regional variation specific to the Pacific Rim countries. The study of speakers' characteristic prosody and how it can be disturbed is under-researched. Very little has been done to quantify the prosodic characteristics. However, for people who have, for example, stroke-impaired speech, the difference between their prestroke and post-stroke prosody can be considerable and disconcerting to those who know them. Speakers can have a degree of control over the type of accent they speak with, although the ability to do this varies and has been little researched.

In this paper, English is the language under consideration, but in addition to the characteristics of individual speaker and regional varieties, languages have their own specific prosodic characteristics. For example, English is often described as a stress-timed language, French syllable-timed (for a discussion of these terms see Abercrombie, 1967; Dauer, 1983; and more recent research, e.g., Dellwo, Fourcin \& Abberton, 2007). Most of the prosodic functions described below are however common to many languages.

\section{Affect Function}

Speech-rate, loudness, pitch-height and pitch-span have been mentioned as important in the indexical function of prosody. They also operate at the level of individual utterances for distinguishing emotion as affective prosody, indicating the feelings of speakers and their attitude to what they are saying (e.g., Mozziconacci, 1998; Banse and Scherer, 1996): broadly speaking, the greater the pitch-span the greater the emotional involvement. Alternative (nonprosodic) ways of conveying affect are many; for example, the choice of lexis and grammatical structures, and body language (facial expressions, posture, gestures). Nevertheless, 'tone of voice' tends to carry great potency, and can sometimes contradict the information carried by 
the words (as in sarcasm). Control is an issue in the affective function of prosody: it is generally reckoned that speakers (especially actors) are probably able to control the degree to which emotion affects their prosody, but that some emotions are overwhelming, or can appear to be so, and that the prosody that results from them is therefore not controllable.

\section{Grammatical Function}

Another function of prosody is to provide grammatical indications: prosody can be the spoken equivalent of written punctuation, and thus indicate where sections of utterances, or phrases, begin and end. Prosody operates in this function essentially over subsections of utterances: these sections may be major or minor syntactic phrases, with, as a rule, major phrase-breaks attracting more prosodic exponents than minor ones. Control of the prosodic parameters affecting phrase-breaks is not usually reckoned to be possible, other than by increasing the amount of silence between prosodic phrases.

Another parallel with punctuation is that the type of phrase can be distinguished by prosody, indicating (for example) whether the utterance is a question or a statement: control of this is possible. For both of these aspects, the alternative means are grammatical: the use of conjunctions and clause structures for indicating the relationship between phrases, and the use of inversion or question particles for indicating sentence-type. A third prosodic function which can be considered grammatical is the use of stress-placement to distinguish word-classes, e.g., noun and verb (e.g., IMprint, imPRINT). This can be varied for contrastive purposes, e.g. "I said EFfect not AFfect").

\section{Pragmatic Function}

Focus as a function of prosody is highly allied to the notion of information structure (Halliday, 1967, and many others since; see summaries in, for example, Cruttenden, 1997), but can also be conceived as a pragmatic aspect of communication. Focus prosody concerns the highlighting of information within utterances, in accordance with the speaker's needs for emphasis, and can thus be regarded as straddling the affective and grammatical functions. Other methods for conveying focus are generally grammatical, such as extraposition and clefting structures, but the use of prosody for highlighting is less ponderous than these and is one of the most salient ways in which prosody has a role in communication; it is also the most researched, and highly controllable.

In brief, focus is indicated by the accented word or syllable in an utterance. In the absence of any need for particular emphasis, the focus of an utterance is said to be broad, as in the neutral utterance 'He asked for coffee'. The accent may not be very prominent; it is generally in final position, but the placement is more canonical than functional: there has to be an accent in an utterance and its default place, as in the above sentence, is near the end. This generalisation is however belied by the placement of accent in noun phrases ('STOrage jars', not 'storage JARS') and 'event' statements, e.g., My FAther's ill', not 'My father's ILL' (Cruttenden, 1997). Prominence of accent is increased if particular emphasis or contrast is required, in which case the focus of the utterance is described as narrow. An example is the utterance 'He asked for TEA' where heavy accent on 'TEA' suggests that it contrasts with a previously mentioned item such as 'coffee'. Narrow focus can be located at any point within an utterance. Information structure suggests that once an item has been mentioned, it is classed as 'given' and deaccented in subsequent mentions, by any interlocutor, e.g., 'No, ANN asked for tea', while 'new' material takes the accent (in this case 'ANN'). Again, it should be noted that in practice the 'rules' of information structure are frequently broken; one has only to think of the (apparently needlessly) prominent prepositions and auxiliaries in the speech of news 
commentators ('the programme CAN be heard ON Radio 3 at 8 o'clock'); and of the way comedians manipulate expectations of given-ness and newness ('Shall we adopt this little girl?' 'But we've already GOT a hamster.') Control of accent placement is thus possible, but the understanding of what is happening and how it is effected is likely to be intuitive rather than a matter of explicit control.

Alternative (non-prosodic) means of indicating focus are mainly structural: clefting may used ('it was Ann who asked for tea'), or word-order may be changed so that the focal material comes last in the utterance ('the one who asked for tea was Ann'). This last device is preferred by speakers of Romance languages, whereas Germanic languages favour the use of prosodic change of stress-placement (Swerts, 2007).

Another pragmatic use of prosody is in illocutionary force, important for the signposting of conversations. The prosody used by interlocutors can indicate whether they intend to continue a turn or yield the floor, and whether they require a contentful response or merely an acknowledgement. This is sometimes considered as a grammatical function, i.e. categorisation of sentence-type.

\section{Prosodic Forms}

To see how disturbance of prosodic function translates into disrupted forms of prosody we need to understand how prosodic forms normally map on to functions. The range of prosodic forms is provided by the acoustic correlates of fundamental frequency (pitch); acoustic energy, intensity or amplitude (volume/loudness); and duration of sounds (length): aspects of these combine in different ways to convey the functions.

Various aspects of these parameters can be directly measured from the speech signal to give information about their role in speech communication. A vast amount of research is devoted to these aspects of prosody and discussion of these will, in this paper, be confined merely to identifying some of the aspects. There is no one-to-one correspondence: many of the forms of prosody map on to several prosodic functions. Furthermore, as previously suggested, individuals vary in their deployment of prosodic forms (e.g., Beckman \& Edwards, 1994). Motor control of individual parameters is possible, and forms the main focus of current strategies for clinical prosodic intervention, but how to do so in a way that keeps prosody both well-formed and functional is not well established.

\section{Pitch}

Pitch (fundamental frequency: f0) can be calculated at single points, giving pitch-heights at particular speech events such as the starts and ends of accented syllables, phrases or topics. Extremes of low pitch in stretches of speech can be subtracted from extremes of high pitch to give a pitch-span or range (but for other ways of calculating span see Patterson, 2000 or Patterson and Ladd, 1999). Pitch-change on particular syllables can be ascertained, giving indications of tones (e.g. low-high $=$ rise, low-high-low = rise-fall, etc.). Pitch can therefore be usefully subdivided into the aspects of pitch-height, pitch-span and pitch-change.

\section{Length}

Duration or length can be measured over individual syllables or stretches of speech, with relative durations of each characterising aspects of speech-timing such as tempo and rhythm. Silence, its presence and duration, has a role to play, in that it is directly implicated in some prosodic effects (boundary, hesitation) and needs to be controlled for in the calculation of speech-tempo and rhythm. For a comprehensive discussion of the role of duration see Fletcher (in press). 


\section{Loudness}

Loudness can be measured in intensity (decibels: $\mathrm{dB}$ ), and has a role in indicating levels of affect and accented material. Spectral balance (the difference in intensity between the band of the spectrum containing fundamental frequency (f0: $0-500 \mathrm{~Hz})$ and each of the bands containing the vowel formants f1, f2, and $\mathrm{f} 3(500-1000 \mathrm{~Hz}, 1000-2000 \mathrm{~Hz}$ and $2000-4000 \mathrm{~Hz}$ respectively: Astruc \& Prieto, 2006) is instrumental in distinguishing stress from accent (Sluijter, van Heuven \& Pacilly, 1997): for stress/accent distinctions see Astruc \& Prieto, 2006. Spectral tilt, the decrease in energy across the spectrum, is another factor in the indication of stress (Sluijter, Shattuck-Hufnagel, Stevens \& van Heuven,1995; Thiessen \& Saffran, 2004).

\section{Phonological prosodic entities}

Phonological prosodic entities are conceptual and not directly measurable: they are conveyed by clusters of prosodic forms, or cues. Not all the cues that can contribute to phonological prosodic entities have to be present in order for them to be conveyed, however, and there may be some cue-trading (enhancement of one cue at the expense of another; see, for example, Beach, 1991). Presence and weight of cues may be influenced by factors such as speaking context, individual vagaries and stylistic variation. In order to carry out effective prosodic intervention, it would be necessary to have a thorough grasp of the clustering and interplay of prosodic forms, and their cue-trading potentials, to convey phonological entities and prosodic functions. Although a vast amount of research has been conducted on individual aspects of these (see for example Fry, 1955; Streeter, 1978; Price, Ostendorf, ShattuckHufnagel \& Fong, 1991; Sluijter et al., 1997; Campbell \& Beckman, 1997) an accessible and comprehensive summary is not available to clinicians.

In addition, the fact that phonological prosodic entities are conceptual gives a hint that other factors have a role in the conception of these entities: these factors include syntactic and pragmatic features, as well as paralinguistic factors such as voice, facial expression, and will be considered later. One of the most difficult aspects of prosody for the clinician is to separate the prosodic from the non-prosodic.

A minimal number of phonological entities distinguished according to current practice are as follows:

Intonational phrase. The highest unit within an utterance is the intonational phrase, which may comprise a whole utterance or be subdivided into a hierarchy: intermediate intonational phrases, accentual phrases, feet, syllables and (in Japanese) morae; this classification varies according to different models, summarised in Shattuck-Hufnagel and Turk (1996). Such phrases and subdivisions are sounded chunks of speech and do not directly derive from grammatical or lexical entities, although the material used in intonation research usually demonstrates a close relationship between syntax and prosody.

Pitch accent and stress. Each intonational phrase contains at least one pitch accent, a syllable which comprises the audible focus of the phrase. Stressed syllables can thus be accented or unaccented, and a good recent account of the acoustic differences between stress and accent can be found in Astruc and Prieto (2006).

Each word contains a stressed syllable; the acoustic correlates of stress are generally higher pitch, extra loudness and length (see Fry, 1955; Lieberman, 1960; Campbell \& 
Beckman, 1997), with different exponents in some languages: in Welsh, for example (Williams, 1985), stress is signalled by relatively lower pitch.

Edge tones: Phrasal and boundary. These demarcate phrases; a few features indicate phrasestart, but most prosodic boundary features concern the ends of phrases. The main exponents are pause and final lengthening: (see Streeter, 1978; Price, Ostendorf, Shattuck-Hufnagel \& Fong, 1991, and many others since). For example, in the phrase 'coffee cake and jam', the first two words can sound like a single item or two separate items depending on whether or not the first word has an edge tone (in this case a phrasal tone, indicating a minor syntactic break): the prosodic features of this tone might consist of a pause between them and lengthening of the second syllable of 'coffee'. Pitch also has a role to play here: it was said earlier that all intonational phrases have a pitch accent, and for 'coffee' to sound as a separate phrase it has to have a pitch accent, which usually involves a change of pitch over the word or syllable.

\section{Neurology and Conditions of Prosodic Disorder}

\section{Neurological Bases of Prosodic Disorder}

Knowledge of the bases of neurological disorder is necessary for the clinician: knowing what areas of the brain control what aspects of prosody will help determine what communicative effects are likely to ensue from specific areas of brain damage. Until the advent of fMRI, attempts to establish the neurological bases of prosodic disorder were dependent on marrying up lesion sites following cerebro-vascular accidents (strokes) with manifestations of prosodic disorder. These early studies suggested that emotional prosody (i.e. prosody associated with affective functions) was processed in the right hemisphere and linguistic prosody (associated with grammatical functions) in the left. Imaging studies have mainly confirmed and fleshed out this picture.

\section{Receptive prosody}

An overview of work in this area is given in Wildgruber, Ackermann, Kreifelts \& Ethofer (2006). Mitchell, Elliott, Barry, Cruttenden \& Woodruff (2003) examine emotional prosody in well-defined contexts and normal neuroanatomy, and found that it was processed mainly in the right hemisphere, specifically the lateral temporal lobes. Wildgruber et al. (2004) found that distinct frontal regions contribute to higher level processing of intonational information depending on its communicative function: that discrimination of linguistic accentuation seems to be lateralized to the left inferior-lateral frontal region whereas bilateral orbito-frontal areas subserve evaluation of emotional expressiveness. In addition, a pitch working memory system was assigned to the right dorsolateral frontal region (BA 9/45/46). A later study (2005) by the same team found that although both hemispheres were involved in the receptive processing of emotional expressiveness, comprehension of affective prosody was bound to a distinct right-hemisphere pattern of activation, encompassing posterior superior temporal sulcus (Brodmann Area [BA] 22), dorsolateral (BA 44/45), and orbitobasal (BA 47) frontal areas; and that activation within left-sided speech areas was observed during phonetic monitoring of the same stimuli. The authors conclude that partially distinct cerebral networks subserve processing of phonetic and intonational information during speech perception, at least where emotion is concerned. 


\section{Expressive prosody}

Relatively less research has been conducted on the neurological basis of production than on the reception of prosody. Dogil, Ackermann, Grodd, Haider, Kamp, Mayer, Riecker \& Wildgruber (2001) obtained results suggesting that it is not the function of prosody (linguistic vs affective) that determines the hemisphere where prosody is generated, but that more general characteristics of the processing units such as the size of the prosodic frame are responsible for the activation of different cortical regions. A later study by essentially the same team (Mayer, Wildgruber, Riecker, Dogil, Ackermann \& Grodd, 2002) appears to have produced conflicting results: clear evidence for the functional lateralization of prosody processing. They found that generating linguistically geared prosody revealed exclusively left hemisphere activation, while the production of affective prosody revealed right hemisphere activation only; and that the generation of prosody involved relatively small, non-overlapping, fronto-basal areas of both the right and the left hemisphere.

\section{Prosodic Disorder}

Prosodic disorder is nearly always seen, clinically, as a problem of expression. Those with expressive prosodic disorder may have receptive prosodic impairment, but this is seldom considered as a possible associated factor. As we have seen in the previous paragraphs, however, research into damaged brains based on perception tasks revealed impairment in receptive as well as expressive abilities. Lesion studies have also revealed the likely locales for prosody centres in the brain, and these are largely supported by recent imaging research. The neurological centres for prosodic ability should be taken into account for clinical and intervention purposes more than they are, and for this a better understanding is needed of how neurological impairment maps on to prosodic ability, and vice versa.

Monrad-Krohn (1963) proposed the following four types of expressive prosodic disorder: hyper-prosody (exaggerated); hypo-prosody (reduced); a-prosody (absence of variation in prosodic exponents) and dys-prosody (inappropriate use of prosodic exponents). Although for Monrad-Krohn dysprosody describes a functional disorder (the other terms suggesting disorder of prosodic forms), this term has recently been used (and will be in this paper) more as a label for formal disorder (Crystal, 1982; Kent \& Rosenbek, 1982). 'Formal disorder' denotes disruption to the manifestation of prosodic exponents (pitch, loudness, duration and silence) as a result of neurophysiological inability to programme or implement motor gestures, rather than a disruption to the planning of such gestures. There has been moreover extended debate as to the overlap between prosody and dysarthria, as summarised in Boutsen (2004). Brewster (1989) anticipates the usage of later writers and includes more classifications for prosodic disorder, which have been adopted here.

Brewster (1989, pp 177-179) divides "prosodic disorder" into three types. In 'prosodic deviation', the prosodic variables that remain to a speaker after impairment occurs are adapted to effect prosodic contrasts (in a form of cue-trading). In 'prosodic disturbance', the disruption of some factor of speech production disturbs prosody, e.g., word-finding difficulties disrupt fluency. 'Prosodic disability' describes the inability to deploy prosodic resources appropriately to achieve linguistic or emotional contrasts. Of these, prosodic deviation is arguably not prosodic disorder but a form of prosodic exploitation, but it is nevertheless likely to produce atypical expressive prosody; prosodic disturbance may be seen as a secondary disorder, the result of some other impairment; and prosodic disability as a primary prosodic disorder. Such considerations are essential for clinical planning: intervention targeting atypical prosodic ability 
might be approached in one way in the case of a primary prosodic disorder, and in quite a different way for secondary prosodic disorder. A further distinction which might be useful for clinicians is whether prosody is well or ill formed, and whether it is well or ill used. 'Ill formed' or 'atypical sounding' are thus terms that can be applied to prosody that sounds odd or unusual or bizarre, regardless of how effective or functional it is; conversely, prosody may sound well formed but not be used in the expected way, and thus be described as 'ill used' or 'atypically used'. Moreover, Brewster's (1989) taxonomy does not allow for specifying which prosodic exponents are affected in dysprosody and which prosodic functions in prosodic disability; nor whether receptive or expressive prosodic disorder is the primary problem.

\section{Prosodic disturbance}

Prosodic disturbance is seen most frequently in acquired disorders such as stroke, dysarthria and Parkinson's disease. Speech in these conditions is generally effortful, with a need for frequent intake of breath and poor breath support. This results in frequent pauses and disfluency. Poor breath support results in a lowering of fundamental frequency on syllables, which can sound like a falling tone. Falling tone and pause constitute two of the main components of phrase-boundary, which may be the reason why such speech gives an impression of frequent phrase finality, although this is usually inappropriate to the linguistic content. In a case study of prosody in dysarthria (Vance, 1994), the participant's need for frequent breaths was great and almost every word was uttered with a falling tone, but the finality thus implied was belied by the lexical or semantic sense. This is at worst misleading and at best a hindrance in processing for the listener; who may nevertheless in time 'tune in' to such idiosyncrasies. Individuals with Parkinson's are often described as depressed, but this could be, at least partly, the effect of low pitch-height, slow rate and small pitch-range in speech, determined by the low energy levels that inhere in the physical nature of Parkinson'sDisease (Scott, Caird \& Williams, 1985; Johnson \& Pring, 1990). That people with this condition have good reason to be depressed is a perfectly reasonable assumption but does not justify invoking the speaker's prosody by way of support. Low pitch-height, slow rate and small pitch-range are the characteristics of depressed speech in healthy individuals (Mozziconacci, 1998), and therefore combine to convey the semblance of depression in people with Parkinson's disease.

It is often assumed that receptive prosody is unaffected in these conditions, but this has been little investigated; if the neurological sites for receptive and expressive prosodic abilities are adjacent, there is a strong possibility that receptive prosody will be affected in stroke victims and need to be taken into account in any intervention program.

\section{Dysprosody and prosodic disability}

The manifestations of dysprosody may be in many senses similar to those of prosodic disturbance, but the causes are different: dysprosody is less occasioned by factors of motor control and more by impairment of the neurological processes directly responsible for prosody, which impairment may be part of particular pathological conditions.

The most purely prosodic of disorders is probably Foreign Accent Syndrome (FAS), a low incidence condition in which a person who has recovered from a cerebro-vascular accident (stroke) in the left hemisphere is perceived to have acquired an accent different from the prestroke one, but show few if any other impairments. The new accent may be perceived as a 
regional variety of the person's native language (e.g., the southern British speaker perceived as having a Scots accent: Dankovicova et al., 2001) or as speaking their native language with a foreign accent (e.g., the Norwegian speaker who spoke with a German accent: Monrad-Krohn, 1947). Different cases seldom exhibit the same set of features, but often include epenthetic syllables; in English, this feature alone this would account for a perception of foreign-ness, since words in many languages other than English tend to end in weak inflexional syllables. For a good review of the prosodic characteristics of FAS, see Verhoeven and Mariën (2002). There is a lack of research into communicatively functional prosodic disorder (prosodic disability) in this population, receptive and expressive, but in general it is thought that speakers with FAS retain and understand prosodic contrasts and use them appropriately.

In autism spectrum disorders, expressive prosody was noted as atypical in the earliest description (Kanner, 1943); most notably researchers have agreed that accent (as used for focus) is affected in this population. It is frequently misplaced (Baltaxe \& Guthrie, 1987), suggesting a prosodic disability or functional disorder, or present in excessive or inadequate amounts (Shriberg et al., 2001), suggesting dysprosody. There have been a few imaging studies which indicate that prosody is processed atypically in people with autism: Wang, Dapretto, Hariri, Sigman \& Brookheimer (2001) found that nine-year-olds with autism processed prosody differently from control children; Gervais et al. (2004) showed that in four adults with autism the voice-selective regions in the superior temporal sulcus failed to be activated in response to voice (as opposed to non-voice) stimuli; Korpilahti (2007) found atypical neural responses to affective prosody in children with Asperger's syndrome. Although the samples are small, this suggests that the expressive dysprosody may well be associated with the processing atypicality. Peppé, McCann, Gibbon, O'Hare \& Rutherford (2007), in a battery of functional and formal prosodic tasks (i.e. targeting both prosodic disability and dysprosody) investigated receptive and expressive prosodic skills and found that children with languagedelayed high-functioning autism were impaired on almost all the tasks compared with agematched peers, suggesting that impaired prosody is an integral part of autism spectrum disorders.

Williams syndrome (WS) is a rare genetic condition (estimated to occur in 1/7,500 births) which causes medical and developmental problems, including an excessively social personality and developmental delay, learning disabilities and attention deficit as well as many physical disorders. Both English and Spanish children (Stojanovik, Setter \& van Ewijk, 2007; Martinez-Castilla, Stojanovik, Setter \& Sotillo, submitted) with WS show prosodic deficits, both receptive and expressive, compared with chronologically age-matched peers, across a full range of prosodic functions. Their expressive prosody appears to be exaggerated, and Setter et al. (2007) found that English children with WS were perceived as being emotionally more involved than both language-matched and age-matched typically-developing children, and also that the pitch-range of the group with WS was greater than that of the typically-developing control groups.

Expressive prosody is sometimes described as atypical in the hearing impaired: according to Monsen (1983), the low intelligibility in speech produced by the deaf is generally ascribed either to aberrant articulation or inappropriate prosody. He however attributes the low intelligibility to the reduced time and frequency of the second formant transitions of the vowels /i/ and /u/ after labial and alveolar consonants (/b, d, f/). 


\section{Impaired perception of prosody}

Apart from neurological studies, where there are more studies in reception than in expression, disorder of prosodic comprehension or perception is under-researched. Some work has been done, however, on the effects of aging on these skills.

Impairments in the ability of elderly people to comprehend affective prosody have been reported, however, and a study by Orbelo, Grim, Talbott \& Ross (2005) confirmed this and found the impairment was not predicted by mild to moderate peripheral hearing loss and was only marginally predicted by traditional cognitive measures. They concluded that loss of affective-prosodic comprehension in elderly persons is related to a specific aging effect that impairs right hemisphere function. In examining the use of prosody with a grammatical function, Titone et al. (2006) found that although older adults use prosodic information to interpret temporary syntactic ambiguities they do so more slowly than younger adults. In addition, older adults appeared to be less able than young adults to revise initial syntactic misinterpretations caused by conflicting prosodic information. The authors discuss the possibility that these differences are caused by age-related impairments in the allocation of working memory resources and inefficient inhibitory function during spoken language processing.

Impairment in the comprehension of affective prosody has been found in people with multiple sclerosis (Beatty, Orbelo, Sorocco \& Ross, 2003), in schizophrenia (Ross et al., 2001) and in people with alcoholism or fetal alcohol exposure (Monnot, Lovallo, Nixon \& Ross, 2002). Correlational analyses in the study by Beatty et al. (2003) suggested that the participants' difficulties in comprehending affective prosodic information were not secondary to hearing loss, aphasic deficits, cognitive impairment, or depression; Monnot et al. (2002) found the level of comprehension was similar to participants with left and right hemisphere brain damage, but that discrimination in all groups was less impaired than in those not exposed to alcohol.

Not surprisingly, hearing impairment is one area where there are more studies of input than of output skills; but these too are few in number and somewhat conflicting in their findings. For example, Most and Peled (2007) found impaired perception of stress and intonation in children with profound hearing loss, whereas Orbelo et al. (2005) found perception of prosody not to be impaired in people with mild to moderate peripheral hearing loss. It may be that it is generally only profound hearing loss that includes loss of lowfrequency hearing (the frequencies at which prosodic exponents occur).

\section{Perception of Prosodic Disorder}

The terms used to describe dysprosody in clinical practice are inadequate and often contradictory. For example, what is meant by such terms as 'singsong' and 'monotonous' can vary radically in terms of prosodic features. 'Singsong' can refer to speech in which pitch-span is very wide (e.g., Welsh-accented) or very narrow ( 'singsong' has been used to describe the way poets read their own work, which they often do with minimal pitch variation, as though wanting to keep all the options for interpretation open). The term 'monotonous' should perhaps to be confined to describing minimal pitch-span - 'monopitch' - implying that speech is all on one tone (level in pitch); sometimes, however, 'monotonous' seems also to designate speech that is syllable-timed (syllables have more or less equal duration) as opposed to stresstimed; and it is never clear which of these two prosodic elements, pitch-span or syllableduration, the describer has most in mind. Monopitch speech, moreover, is not invariably perceived as dysprosodic: many unimpaired speakers have extremely narrow pitch-span. They 
may be deemed to be boring or difficult to listen to, but the problem is not perceived as one of prosodic disorder.

The terms used to describe expressive prosody in autism spectrum disorders include: 'monotonous', 'exaggerated', 'singsong', 'dull', 'robotic' and 'wooden'. Some of these, such as 'exaggerated' and 'monotonous', are contradictory: do the terms mean different things to different people but refer to speech that has the same prosodic characteristics, or is there a wide variation in expressive prosody in autism spectrum disorders? The clinician needs more concrete and established usage for descriptions of impaired prosody in order to be able to address it. By contrast, the processes of articulation (e.g., fronting, palatalisation), are wellestablished and indispensable to the clinician.

What is clear from these descriptions of dysprosody, however, is that there exists a notion of 'prosodic well-formedness'. This may be independent of communication function, i.e. whether or not prosody affects intelligibility; prosodic ill-formedness ('atypical expressive prosody') may hinder understanding to some extent, but this may be less important than its social effect as a marker of difference.

\section{Interaction between Prosody and Other Aspects of Speech}

As already mentioned, all prosodic effects can be achieved by other means in speech, and where many aspects of speech coalesce to prevent ambiguity, prosody need not be consonant with them. Thus a radio presenter may say:

"And the time is. Quarter to nine my next guest is....."

As written, the full stop indicates a prosodic break, complete with final syllable lengthening, tone on the last word and a short silence after it. Obviously this should occur on 'nine', before 'my', but the meaning is so clear from the lexis, the context and the grammatical structures that the misplaced prosodic break barely causes any hindrance in prosodic processing.

Sarcasm capitalises on this dissociation but in reverse, i.e. prosody carries the day over sense: if "I had a lovely time" is said with sarcastic prosody, the tone is a straight indication that the words are not to be taken at face value. It is beyond the scope of this paper to discuss what conditions determine whether prosody, linguistic content or context is the more influential in determining how meaning is perceived, but the clinician needs to bear in mind that prosody, while sounding well formed, may be either legitimately and effectively at odds with linguistic sense, or unintentionally and misleadingly at odds.

Distinctions such as those devised by Monrad-Krohn (1963) and Brewster (1989) may be said to be intra-prosodic, but the relationship between prosody and other aspects of speech also need distinguishing, in order to decide which aspects of disorder are truly prosodic and which belong more properly to other speech parameters. In dealing with prosodic disorder, it is important for the clinician to be able to recognise what is in the domain of prosody and to be able to distinguish it from interacting factors.

\section{Segmental and suprasegmental}

Articulation can have a suprasegmental function. A glottal stop [?], for example, is often a substitute for a consonant but can also operate in the affect function (e.g., "PI Pam Pextremely Pannoyed") the focus function ("he ?IS eighteen") and the phrasing function (in the utterance "coffee ice-cream and cake", 'ice-cream' is likely to be heard as a separate item from 'coffee' if it is preceded by a glottal stop, even when pitch and timing exponents show little 
indication of boundary between the two). Segments can be drawled, or lengthened [:], for effect ("he's so: annoying"). Spectral balance has a role to play in determining accent and stress (Sluijter et al., 1997). It is possible that the intrinsic pitch of segments (Lehiste, 1970) can affect the perception of the relative pitch of syllables.

It is noticeable that people with prosodic disorder frequently display articulatory deviation as well, although why this should be is not established. The co-occurrence makes it particularly important to decide which aspects of disorder are segmental and which suprasegmental. Articulation may not be severely impaired: for instance, articulation in people with autism spectrum disorders is generally thought to be preserved, although prosodic disorder is perceived in them. In a study of articulation in children with autism spectrum disorders (Gibbon, McCann, Peppé, O'Hare \& Rutherford, 2004), however, articulation errors were identified in the speech of $28(41 \%)$ of the children. Out of these 28 children, articulation scores indicated that 20 had articulation abilities within the normal range and 8 had articulation abilities that were delayed by a year or more. 'Atypical' substitutions (developmentally the most immature type of error) were frequent in the delayed group and rare in those with articulation in the normal range. 'Almost mature' errors (the most mature type of error) were rare in the children with delays and frequent in those with articulation in the normal range. The pattern of articulatory errors in this group is thus different from what is often found in children with articulation problems. Other studies have also found articulation to be impaired in children with autism spectrum disorders (e.g., Shriberg et al., 2001). The individual contributions of articulation and prosody to perceived atypicality are not well understood, and offer a fruitful area of possible research. Impaired articulation may mask the existence and problems of impaired prosody.

\section{Prosody and grammar}

As mentioned above, where the interaction between prosody and grammar is concerned (the chunking of speech, sentence-type), prosody can be frequently at odds with the linguistic sense of an utterance but this seldom hinders the interpretation of the speaker's meaning. Indeed, in some speaking styles, consonance between prosody and grammar is seen as redundant, and unnecessarily pedantic. The vogue for the uptalk or high rising terminal (described earlier: Cruttenden, 1994) illustrates the fact that the potential ambiguity it occasions is no compelling reason to eschew its use. What prompted the vogue is an interesting question that will not be explored here.

Where agrammatism is present, however, there is a secondary effect on prosody, usually on rhythmical aspects. One of the manifestations of agrammatism is the loss of function words (articles, pronouns, verb inflections) that typically carry no stress: a condition that is also seen in children with specific language impairment (SLI). As pointed out in the work of Leonard and others (e.g., McGregor \& Leonard, 1994), speakers with this disorder will produce successions of stressed words, resulting in atypical speech-rhythm. There is also the relationship between prosody and the development of language to take into consideration: the prosodic bootstrapping hypothesis (e.g., Jusczyk, Hirsh-Pasek, Kemler Nelson, Kennedy, Woodward, \& Piwoz, 1992) argues that infants who lack sensitivity to prosodic differences are disadvantaged in segmenting the speech-stream that is the child's first experience of language, and that this prosodic disability may be at the root of language impairment: another area where further research could be useful. 


\section{Prosody and lexis}

In lexical tone languages, aspects of prosody (specifically tone) have a role in wordidentification. Tone does not have such a role in English, although stress placement can, as already indicated, distinguish word-class (IMprint-imPRINT), and lexis in a very few cases (below-billow). There are, however, canonical stress-patterns for words and phrases, and that these have a role in word-identification is illustrated by the story of the non-native speaker of English visiting London who asked for a ticket to 'Tottenham COURT Road' (the normal stress-pattern of which is 'Tottenham Court ROAD') and, since the noisy environment prevented anything but the stress-pattern being heard, was issued with one for 'Kensington HIGH Street'. Although this is an exaggerated example, incorrect stress-patterns can affect intelligibility, or at least hinder processing in the hearer.

Conversely, it is also of course possible for words to influence the way prosody is heard. The utterance "You said you would tell me" is quite likely to be perceived by a listener as having been said with a reproachful or angry tone, whatever its prosodic features.

\section{Prosody and voice/articulatory setting}

Voice quality is characteristic of speakers; for example, some voices are constantly creaky or resonant, and therefore indexical in function. Mackenzie Beck (2005) and Laver (1980) describe 'default' voice quality, or voice with no distinguishing features, as 'modal voice', and voice qualities other than modal have generally some good reason for their presence: the reason may have no communication value and be pathological, (e.g., the result of laryngitis), or be associated with mainly affective and paralinguistic functions. Hence breathy voice suggests excitement, and husky voice can indicate emotion strong enough to cause weeping. A whisper usually implies an environment where the loudness of normal speaking would be inappropriate. Non-modal or atypical voice quality is often viewed as part of disordered prosody, and, like articulatory disorder, often co-occurs with it. For example, in a study of children with high-functioning autism a relatively high percentage were found to have atypical voice quality as well as atypical prosody (McKinnon, 2005). The role of voice quality in communication does not extend to the more linguistic functions we have identified for prosody.

Articulatory setting can have a role in indexical and affective aspects of communication: in adopting a regional accent, actors may assume a particular shape for their vocal tract; and 'smile voice', indicating that the speaker has lips spread and is smiling, can be heard in, for example, telephone conversations.

\section{Prosody and visual cues}

Finally, visual prosody interacts with speech prosody, sometimes obviating the need for the latter: raised eyebrows can indicate questioning as effectively as rising tone. Thus the utterance "She's not in today" can be said with definite-sounding falling tone as if it were a statement, but still convey a question if the speaker has raised eyebrows and looks at the interlocutor when speaking. Conversely, high rising terminals often do not denote questions, as has been well established, and speakers who use it in this way frequently reinforce the nonquestion status by nodding, thus doing the answering if any were necessary (e.g., 'I'm an eventólogist' [nod]; the implication being: 'you may not have heard of that profession but I assure you it is one'). Gaze direction, and its duration, can also affect turn-taking: it can imply which speaker is to speak next. Gestures also contribute to visual prosodic cues: thumping the table operates as verbal emphasis. Clearly, many affective cues can be gained from facial expressions. 
Prosodic Disorder and Phonological Prosodic Categories

Phonological prosodic categories are not fixed to the degree that, for example, segmental ones are (even allowing for allophonic variation), but remain elusive. If articulation is mildly impaired, consonants are perceived as departing from a norm. There are many degrees of segmental abnormality, the more extreme of which are considered to warrant clinical intervention, but all are seen as impaired renditions of the target consonant. Sometimes the impairment makes the target seem like a different consonant, but for this to be communicatively misleading the word in which it occurs has to be minimally-paired (segmentally) with another word differentiated on that consonant; and that other word has to be to valid in the context in which it occurs. For example, cape will be heard as cake in the context "Have some more cape", but not in the context of "Say 'cape' again". Since the main communicative function of segments is word-identification, speech may become unintelligible if a number of consonants are impaired, but the identity of the word in context acts as a yardstick or cross-reference by which the correctness of the articulation may be measured.

Only a few aspects of prosody, however, such as canonical stress in words and phrases, or lexical tone in tone languages, have a fixed norm and role in the way that segments do. When English canonical stress-placement changes (usually through diachronic forces: another interesting question that will not be discussed here), as when, for example, conTRIbute becomes CONtribute, it is often perceived as 'wrong', even though the change causes little or no misunderstanding or hindrance to word-identification and is soon accepted.

Most aspects of prosody, however, lack a correctness yardstick: the effect of this can be that the prosodic features are interpreted as operating in an alternative function as opposed to being perceived as an error. Prosodic variation that is lacking or over-prominent may lead to the loss of a linguistic-prosodic distinction, but this loss may not be perceived as such; instead, the prosodic elements may be seen as operating in another system, e.g., an affective-prosodic one. An unimpaired native speaker who says storage JARS will be perceived not as having got it wrong but as wanting to stress the word jars for some (perhaps unclear) reason. In clinical populations this creates confusion. For example, one manifestation of prosodic disorder in autism has been described as excessive stress: more syllables sound accented than is warranted by either the grammatical function of phrasing (boundary), the pragmatic function of focus (contrastive stress), or the lexical requirement of word-stress. The result for the listener may be some hindrance in determining the focus and the boundary, but there may additionally be an impression of insistence (conveyed by the multiple accents), and with that an impression of high emotional involvement (affect) on the part of the speaker, conveyed by the wide pitchspan that will be incurred by a succession of accents. Because the workings of prosody are so little discussed, listeners are unlikely to interpret this as impaired speech, as would perhaps be the normal reaction to a mispronounced consonant or a grammatical error: they are more likely to think the manner of such speakers inappropriate or rude, unless the prosodic impairment is accompanied by some other problem (e.g., segmental errors).

Transcription and Assessment of Atypical Prosody, and Approaches to Treatment

Clinicians are faced with requests for intervention to address problems of prosodic disorder but will often find, perhaps for the above reasons, that atypical prosody does not fit into the phonological categories of prosody that they have encountered in training. They often find themselves dealing with clients whose utterances are curtailed as a result of various pathologies. Prosody needs to be particularly taken into account in short utterances, where linguistic structures and variation in vocabulary are reduced and prosody can enhance meaning. 


\section{Transcription}

The transcription of prosody has taken several forms, which will not be discussed here. Currently, the most widely used is Pierrehumbert's Tone-Break Index system (ToBI: Beckman \& Hirschberg, 1993), which has the advantage of having very few symbols which can easily be recognised in all languages, although recent developments of it and language-specific versions are increasingly complex. The extended IPA (Duckworth, Allen, Hardcastle \& Ball, 1990) includes notation for prosodic features and is intended to be suitable for the transcription of disordered speech (Ball, Rahilly \& Tench, 1996). The transcription of prosody is seen as a necessary skill for all speech-language pathology students, possibly because if the aural is fixed in a visual form, it is clearly easier for study, and assigning phonological categories gives the impression of 'making sense' of the pitch patterns.

What a clinician needs to know about someone with suspected impaired prosody is whether or not their prosodic exponents coincide with the listener's phonological-prosodic expectations; and if not, whether this is due to a sophisticated use of prosody (as indicated earlier) or prosodic impairment. 'Phonological' transcription systems such as the extended IPA, the British school of intonation and ToBI (which has become a phonological system, having been originally designed to be phonetic), do not allow for this.

The impressionistic system purports to give a phonetic rendition: pitch and loudness changes and speech rate are indicated on a stave above the words (relative syllable-duration is less well indicated), with silences indicated in the orthography (Ball et al., 1996). This representation is better effected by wave-form/fundamental frequency analysers, which are more objective than a listener: there are many computer programs that do this, (e.g., PRAAT by Boersma \& Weenink, 2001). Most phonetic systems are, however, deemed incomplete without some phonological categorisation, making the transcription process again subjective; and indeed it is not particularly useful to know that pitch is high at a certain point without being able to ascertain in which system the pitch is operating at that point: whether it indicates a stressed/accented syllable, initiality of phrase, the first part of a falling tone or the last part of a rise.

Many of the available transcription systems fall between the two stools of phonology and phonetics, or function and form. For example, a transcriber will frequently find that $\mathrm{s} / \mathrm{he}$ can hear where the main accent of a phrase is, or should be, but the prosodic exponents or the word supposed to carry the accent may be missing. For example, the rising-tone utterance: "thank you" may emerge as "....'k you". This could be transcribed with an accent on the (mainly missing) thank - a phonological approach - or on the you, which is phonetically more prominent than thank (you is higher, louder and longer than thank in this case). Yet listeners would all agree that you is not accented. So is the transcription to indicate where the accent should be or where the prosodic exponents are? A view can be taken as to how to approach this, but many student clinicians are discouraged in their study of prosody when, as frequently happens, half the class hears a tone as a fall and the other half as a rise. Exactly what listeners are tuning into when their perceptions differ so much is not clear. In brief, most prosody transcription systems seem to be of little help in identifying prosodic disorder.

\section{Assessments}

Evaluations that are designed purely with prosody in mind tend to focus on expressive skills: Crystal's Profiling of Prosody, or PROP (Crystal, 1982), and Shriberg's Prosody-Voice Screening Test, or PVST (Shriberg, Kwiatkowski \& Rasmussen, 1990). Both of these tests make use of the testee's spontaneous speech and require the tester to be able to transcribe the prosody. The experiments mentioned earlier which assessed the reception of affective prosody 
in alcohol-related conditions and schizophrenia (Monnot et al., 2002; Ross et al., 2001) used the Aprosodia Battery (Ross, Thompson \& Yenkosky, 1997) which is not generally available.

Assessments of acquired disorders where prosody is impaired sometimes include protocols for testing prosody: for example, the Frenchay Dysarthria Assessment (Enderby, 1983). These tend to be less than comprehensive.

The PEPS-C assessment procedure (Peppé \& McCann, 2003) has as its main advantage that it bypasses the problems of phonological categorisation and transcription, making it more practical for clinical use than existing tests. It investigates receptive and expressive prosody skills in parallel tasks, the idea being that it is necessary to have a profile of both receptive and expressive ability in case one informs the other in an individual. The tasks consist of perceiving or expressing meanings as conveyed by prosody without reference to phonological entities. The expressive tasks use elicited as opposed to spontaneous utterances. Where receptive prosody is concerned, testees select pictures on a computer screen portraying meaningdifferences associated with prosodic variation. Auditory stimuli purport to convey these meaning-differences to a degree that is unambiguous without being exaggerated. Auditory discrimination tasks indicate whether testees perceive at least basic prosodic differences, and imitation tasks evaluate a testee's ability to imitate prosody. The test can thus indicate where prosodic expression is misleading (ill used and possibly ill formed), but is less good at indicating in what respects prosody is simply ill-formed. Performance is judged by reference to that of a control group of unimpaired testees. It is possible to analyse acoustically the recordings of the testee's responses to identify what prosodic exponents are deviating and in what way, thus explaining how they give rise to misleading or atypical prosody. In order to make use of acoustic analysis, however, much more needs to be known about how much variation in which elements is necessary for prosody to be judged atypical, or for phonological prosodic entities to fail to convey their meaning.

\section{Prosodic Intervention}

Little has been attempted in the way of using prosody directly to target prosodic problems. One type of intervention is Melodic Intonation Therapy (MIT: Albert, Sparks, \& Helm, 1973), used successfully to encourage a non-verbal child with autism spectrum disorders to become verbal (Miller \& Toca, 1979). MIT seeks to stimulate speech production by the musical activation of the right hemisphere of the brain: the client hums the pitch patterns and taps the rhythms of phrases, eventually graduating to a more speech-like production.

There are a number of disparate, ad hoc intervention procedures to remedy prosodic problems, and there is a handbook of suggestions for how to involve prosody in intervention (Hargrove \& McGarr, 1994) but it lacks evidence for the acceptability or efficacy of such techniques. A search for prosody therapy revealed very few studies; in one, therapy focused narrowly on the expression of one aspect of prosody (stress-placement) (Hargrove, Roetzel \& Hoodlin, 1989) with some degree of success.

The focus of intervention has thus been mainly on expressive skills. Training in expressive prosody may, however, give limited and misleading notions of what prosody is and can do, and the lack of clear understanding about how the various prosodic elements operate within prosodic functions makes it inadvisable to advocate anything very concrete about, for example, speaking more loudly or more slowly. Furthermore, as previously mentioned, the extent of control a normal speaker has over prosody is limited, and prosody that is controlled may have an adverse effect on listeners (sounding, at the least, insincere if not inappropriate). A better approach might be to focus on receptive skills. In a study that assessed both receptive and expressive prosody skills using PEPS-C (Peppé et al., 2007), receptive skills were shown 
to be significantly correlated in both the experimental and control group. It is therefore possible that expressive problems may be improved by intervention based on receptive skills.

\section{Conclusion}

There has thus been considerable progress in identifying the neurological bases of prosodic disorder, conditions in which prosodic impairment occurs, and the relationship between prosody and other aspects of speech. There has also been classification (at a high and general level) of types of prosodic disorder. As far as the characterisation of prosodic disorder is concerned however, the picture is not so good. I have emphasised here the need for clinicians to bear in mind all the non-prosodic factors that impinge on the realisation of prosody; and that it is nearly always possible to find prosodic 'rules' transgressed in perfectly normal usage, and conversely, that when characterisations of atypical prosody are made, it is nearly always possible to find examples of them in typical speech. These problems are wellknown in other areas of speech such as segmental phonetics, but the lack of 'correctness' yardsticks in prosody makes for particular problems in determining what is atypical. When enough is known about how prosodic forms map on to prosodic functions or on to perceived well-formedness of prosody, it may be possible eventually to establish objective criteria for the nature of prosodic disorder.

\section{References}

Abercrombie, D. (1967). Elements of general phonetics. Edinburgh: Edinburgh University Press.

Albert, M. L., Sparks, R. W., \& Helm, N. A. (1973). Melodic intonation therapy for aphasia. Archives of Neurology, 29, 130-131.

Astruc, L. \& Prieto, P. (2006.) Acoustic cues of stress and accent in Catalan. In R. Hoffmann \& H. Mixdorff (Eds.) Proceedings of Speech Prosody 2006 (pp. 337-340). Dresden: Verlag der Wissenschaften GmbH TUDpress.

Ball, M., Rahilly, J. \& Tench, P. (1996). The Phonetic Transcription of Disordered Speech. San Diego: Singular Publishing.

Banse, R., \& Scherer, K. R. (1996). Acoustic profiles in vocal emotion expression. Journal of Personality and Social Psychology, 70, 614-636.

Baltaxe, C. A. M. \& Guthrie, D. (1987). The use of primary sentence stress by normal, aphasic and autistic children. Journal of Autism and Developmental Disorders, 17(2), 255-271.

Beach, C. M. (1991). The interpretation of prosodic patterns at points of syntactic structure ambiguity: Evidence of cue trading relations. Journal of Memory and Language, 30, 644-663.

Beatty, W. W., Orbelo, D. M., Sorocco, K. H. \& Ross, E. D. (2003). Comprehension of affective prosody in multiple sclerosis. Multiple Sclerosis, 9(2), 148-153.

Beckman, M.E. (1986). Stress and Non-Stress Accent. Netherlands Phonetic Archives 7. Dordrecht: Foris

Beckman, M. E. \& Edwards, J. (1994). Articulatory evidence for differentiating stress categories. In P. Keating (Ed.), Papers in Laboratory Phonology II, (pp. 7-33). Cambridge, UK: Cambridge University Press.

Beckman, M. E., \& Hirschberg, J. (1993). The ToBI Annotation Conventions. Unpublished manuscript. Retrieved 28 March 2008 from http://ling.ohiostate.edu/Phonetics/etobi homepage.html.

Boersma, P. \& Weenink, D. (2001). PRAAT, a system for doing phonetics by computer. Glot International, 5(9/10), 341-345. 
Boutsen, F. (2004). Aprosody: A right hemisphere dysarthria. Journal of Medical Speech Language Pathology, 12, 67-76.

Brewster, K. (1989). The assessment of prosody. In K. Grundy (Ed.), Linguistics in clinical practice $\left(1^{\mathrm{st}} \mathrm{ed}.\right)$. London: Taylor and Francis.

Campbell, N. \& Beckman, M. (1997). Stress, prominence and spectral balance. In A. Botinis, G. Kouroupetroglu \& G. Carayiannis (Eds.), Intonation: Theory, Models and Applications (pp. 67-70). Athens: ESCA and University of Athens.

Couper-Kuhlen, E. (1986). An introduction to English prosody. London: Edward Arnold. Cruttenden, A. (1994). Rises in English. In J. Windsor Lewis (Ed.), Studies in general and English phonetics: Essays in Honour of Professor J.D. O'Connor (pp. 155-173). London: Routledge.

Cruttenden, A. (1997). Intonation ( $\left.2^{\text {nd }} e d\right)$. Cambridge: Cambridge University Press. Crystal, D. (1969). Prosodic Systems and Intonation in English. Cambridge: C.U.P. Crystal, D. (1982). Profiling Linguistic Disability. London: Edward Arnold.

Dankovicova, J., Gurd, J. M., Marshall, J. C., MacMahon, M. K. C., Stuart-Smith, J., Coleman J. S., Slater, A. (2001). Aspects of non-native pronunciation in a case of altered accent following stroke (foreign accent syndrome). Clinical Linguistics and Phonetics, $15,195-218$.

Dauer, R.M., (1983). Stress-timing and syllable-timing re-analysed. Journal of Phonetics, 11, $51-62$.

Dellwo, V., Fourcin, A. \& Abberton, E. (2007). Rhythmical classification of languages based on voice parameters. In J. Trouvain \& W. J. Barry (Eds.), Proceedings of the XVIth ICPhS (pp. 1129-1132). Saarbrücken: University of Saarland.

Dogil, G., Ackermann, H., Grodd, W., Haider, H., Kamp, H., Mayer, J., Riecker, A. \& Wildgruber, D. (2001). The speaking brain: A tutorial introduction to fMRI experiments in the production of speech, prosody and syntax. Journal of Neurolinguistics, 15(1), 5990 .

Duckworth, M., Allen, G., Hardcastle, W. \& Ball, M. J. (1990). Extensions to the International Phonetic Alphabet for the transcription of atypical speech. Clinical Linguistics and Phonetics, 4, 273-280.

Enderby, P. M. (1983). Frenchay Dysarthria Assessment. San Diego: College Hill Press.

Fletcher, J. (to appear). The prosody of speech: Timing and rhythm. In W. J. Hardcastle, J. Laver \& F.Gibbon (Eds.), The Handbook of Phonetic Sciences $\left(2^{\text {nd }}\right.$ ed). Oxford: Blackwell

Fry, D.B. (1955). Duration and intensity as physical correlates of linguistic stress. Journal of the Acoustical Society of America, 27, 765-768.

Gervais, H., Belin, P., Boddaert, N., Leboyer, M., Coez, A., Sfaello, I., Barthélémy, C., Brunelle, F., Samson, Y. \& Zilbovicius, M. (2004). Abnormal cortical voice processing in autism. Nature Neuroscience, 7(8), 801-802.

Gibbon, F., McCann, J., Peppé, S., O'Hare, A. \& Rutherford,M. (2004). Articulation abilities of children with high-functioning autism. In B. Murdoch, J. Goozee, B. Whelan, \& K. Docking (Eds.), $26^{\text {th }}$ World Congress Proceedings of the International Association of Logopedics and Phoniatrics. Brisbane, Australia.

Halliday, M. A. K. (1967). Intonation and Grammar in British English. The Hague: Mouton. Hargrove, P. M., \& McGarr, N. S. (1994). Prosody Management of Communication Disorders. London: Whurr.

Hargrove, P. M., Roetzel, K., \& Hoodlin, R. B. (1989). Modifying the prosody of a languageimpaired child. Language, Speech, and Hearing Services in Schools, 20, 245-258. 
Johnson, J.A. \& Pring, T. R.(1990). Speech therapy and Parkinson's disease: A review and further data. British Journal of Disorders of Communication, 25, 183-194.

Jusczyk, P. W., Hirsh-Pasek, K., Kemler Nelson, D., Kennedy, L., Woodward, A., \& Piwoz, J. (1992). Perception of acoustic correlates of major phrasal units by young infants. Cognitive Psychology, 24, 252-293.

Kanner, L. (1943). Autistic disturbances of affective contact. Nervous Child, 2, 217-250.

Kent R. D. \& Rosenbek, J. C. (1982). Prosodic disturbance and neurologic lesion. Brain and Language, 15, 259-292.

Korpilahti, P. (2007). Processing of affective speech prosody is impaired in Asperger syndrome. Journal of Autism and Developmental Disorders, 37(8), 1539-1549.

Laver, J. (1994). Principles of Phonetics. Cambridge: C.U.P.

Laver, J. (1980). The Phonetic Description of Voice Quality. Cambridge: Cambridge University Press.

Lehiste, I. (1970). Suprasegmentals. Cambridge: MIT Press.

Lieberman, P. (1960). Some acoustic correlates of word stress in American English. Journal of the Acoustical Society of America, 32, 451-454.

Mackenzie Beck, J. (2005). Perceptual analysis of voice quality: The place of the Vocal Profile Analysis. In W. J. Hardcastle \& J. Mackenzie Beck (Eds.), A Figure of Speech (pp. 285322). New Jersey: Lawrence Erlbaum Associates.

Martínez-Castilla, P., Stojanovik, V., Setter, J., \& Sotillo, M. (submitted). Prosodic abilities in Spanish and English children with Williams Syndrome: A cross-linguistic study. Paper submitted for publication.

Mayer, J., Wildgruber, D., Riecker, A., Dogil, G., Ackermann, H. \& Grodd, W. (2002). Prosody production and perception: Converging evidence from fMRI studies. International Speech Communication Association Archive, Speech Prosody, Aix-enProvence.

McGregor C. \& Leonard, L. (1994) Subject pronoun and article omissions in the speech of children with specific language impairment: A phonological interpretation. Journal of Speech and Hearing Research, 37, 171-81.

McKinnon, A. (2005). Vocal Profiling in Children with language-delayed high-functioning Autism. Unpublished MSc dissertation, Queen Margaret University, Edinburgh.

Miller, S. B., and Toca, J.M. (1979). Adapted Melodic Intonation Therapy: A case study of an experimental language program for an autistic child. Journal of Clinical Psychiatry, 40, 201-203.

Mitchell, R. L. C., Elliott, R., Barry, M., Cruttenden, A. \& Woodruff, P. W. R. (2003). The neural response to emotional prosody, as revealed by functional magnetic resonance imaging. Neuropsychologia, 41(10), 1410-1421.

Monnot, M., Lovallo, W. R., Nixon, S. J., Ross, E. (2002). Neurological basis of deficits in affective prosody comprehension among alcoholics and fetal alcohol-exposed adults. Journal of Neuropsychiatry and Clinical Neuroscience, 14, 321-328.

Monrad-Krohn, G. H. (1947). Dysprosody or altered 'melody of language'. Brain, 70, 405415.

Monrad-Krohn, G.H. (1963) The third element of speech: Prosody and its disorders. In L. Halpern (Ed.), Problems in Dynamic Neurology (pp. 101-117). Jerusalem: Hebrew University Press.

Monsen, R.B. (1983). The oral speech intelligibility of hearing-impaired talkers. Journal of Speech and Hearing Disorders, 48, 286-296. 
Most, T. \& Peled, M. (2007). Perception of suprasegmental features of speech by children with cochlear implants and children with hearing aids. Journal of Deaf Studies and Deaf Education, 12(3), 350-361.

Mozziconacci, S. J. L. (1998). Speech variability and emotion: Production and perception. Unpublished Ph.D. thesis, Eindhoven, The Netherlands.

Orbelo, D. M., Grim, M. A., Talbott, R. E. \& Ross, E. D. (2005). Impaired comprehension of affective prosody in elderly subjects is not predicted by age-related hearing loss or agerelated cognitive decline. Journal of Geriatric Psychiatry and Neurology, 18(1), 25-32.

Patterson, D. (2000) A Linguistic Approach to Pitch Range Modelling. PhD dissertation, University of Edinburgh.

Patterson, D., \& Ladd, D.R. (1999). Pitch range modelling: linguistic dimensions of variation. Proceedings of the XIXth ICPhS (pp. 1169-1172). Berkeley University: San Francisco.

Peppé, S., \& McCann, J. (2003). Assessing intonation and prosody in children with atypical language development: The PEPS-C test and the revised version. Clinical Linguistics and Phonetics, 17, 345-354.

Peppé, S., McCann, J., Gibbon, F., O’Hare, A. \& Rutherford, M. (2007). Receptive and expressive prosodic ability in children with high-functioning autism. Journal of Speech, Language, and Hearing Research, 50, 1015-1028.

Pierrehumbert, J. (1980). The Phonology and Phonetics of English Intonation. $\mathrm{PhD}$ thesis, Cambridge, Ma: MIT Press

Price, P. J., Ostendorf, M., Shattuck-Hufnagel, S. \& Fong,C. (1991). The use of prosody in syntactic disambiguation. Journal of the Acoustic Society of America, 90, 2956-2970.

Ross, E. D., Orbelo, D. M., Cartwright, J., Hansel, S., Burgard, M., Testa, J. A. \& Buck, R. (2001). Affective-prosodic deficits in schizophrenia: Profiles of patients with brain damage and comparison with relation to schizophrenic symptoms. Journal of Neurolinguistics, Neurosurgery and Psychiatry, 70, 597-604.

Ross, E. D., Thompson, R. D. \& Yenkosky, J. (1997). Lateralization of affective prosody in brain and the callosal integration of hemispheric language functions. Brain and Language, 56, 27-54.

Scott, S., Caird, F. I. and Williams, B. O. (1985). Communication in Parkinson's Disease. London: Croom Helm.

Shattuck-Hufnagel, S. \& Turk, A. (1996). A prosodic tutorial for investigations of auditory sentence processing. Journal of Psycholinguistic Research, 25, 193-247.

Setter, J., Stojanovik, V., van Ewijk , L., Moreland, M. (2007). Affective prosody in children with Williams syndrome. Clinical Linguistics \& Phonetics, 21(9), 659- 672.

Shriberg, L. D., Kwiatkowski, J. \& Rasmussen, C. (1990). The Prosody-Voice Screening Profile. Tucson, AZ: Communication Skill Builders.

Shriberg, L. D., Paul, R., McSweeny, J. L., Klin, A., Cohen, D. J. \& Volkmar, F. R. (2001). Speech and prosody characteristics of adolescents and adults with high-functioning autism and Asperger's Syndrome. Journal of Speech, Language, and Hearing Research, 44, 1097-1115.

Sluijter, A. M. C., Shattuck-Hufnagel, S., Stevens, K. N. \& van Heuven, V. J. (1995). Supralaryngeal resonance and glottal pulse shape as correlates of stress and accent in English. Proceedings of the XIIIth ICPhS, Dept of Speech Communication and Music Acoustics (pp. 630-633). Stockholm University: KTH and Department of Linguistics.

Sluijter, A. M. C., van Heuven, V. \& Pacilly, J. J. A. (1997). Spectral balance as a cue in the perception of linguistic stress. Journal of the Acoustic Society of America, 101(1), 503513. 
Streeter, L. A. (1978). Acoustic determinants of phrase boundary perception. Journal of Acoustical Society of America, 64(6), 1582-1592.

Stojanovik, V., Setter, J., \& van Ewijk, L. (2007). Intonation abilities of children with Williams syndrome: a preliminary investigation. Journal of Speech, Language, and Hearing Research, 50, 1606-1617.

Thiessen, E. D. \& Saffran, J. R. (2004). Spectral tilt as a cue to word segmentation in infancy and adulthood. Perception \& Psychophysics, 66(5), 779-791.

Titone, D. A., Koh, C. K., Kjelgaard, M. M., Bruce, S., Speer, S. R., \& Wingfield, A. (2006). Age-related impairments in the revision of syntactic misanalyses: Effects of prosody. Language and Speech, 49(1), 75-99.

Vance, J. (1994). Prosodic deviation in dysarthria: A case study. European Journal of Disorders of Communication, 29, 61-76.

Verhoeven, J. \& Mariën, P. (2002). Prosodic characteristics of a case of Foreign Accent Syndrome. Antwerp Papers in Linguistics, 100, 131-148.

Wang, A., Dapretto, M., Hariri, A., Sigman, M. \& Brookheimer, S. (2001). Processing affective and linguistic prosody in autism: An fMRI study. Neuroimage, 13(6), S621S621.

Wildgruber, D., Ackermann, H., Kreifelts, B. \& Ethofer, T. (2006). Cerebral Processing of linguistic and emotional prosody: fMRI studies. Progress in Brain Research, 156, 249 268.

Wildgruber, D., Hertrich, I., Riecker, A., Erb, M., Anders, S., Grodd, W., \& Ackermann, H. (2004). Distinct frontal regions subserve evaluation of linguistic and emotional aspects of speech intonation. Cerebral Cortex, 14(12), 1384-1389.

Wildgruber, D., Riecker, A., Hertrich, I., Erb, M., Grodd, W., Ethofer, T. \& Ackermann, H. (2005). Identification of emotional intonation evaluated by fMRI. NeuroImage, 24, $1233-1241$.

Williams, B. (1985). Pitch and duration in Welsh stress perception: The implications for intonation. Journal of Phonetics, 13, 381-406 